\title{
Pharmacist Intervention Documentation in Saudi Arabia
}

Yousef Ahmed Alomi*, ID BSc. Pharm, MSc. Clin Pharm, BCPS, BCNSP, DiBA, CDE, Critical Care Clinical Pharmacists, TPN

Clinical Pharmacist, Freelancer Business Planner, Content Editor and Data Analyst, Riyadh, Saudi Arabia.

Ebtissam Mohammad Badawoud, B. Sc. Pharm, MSc, Pharmacist, Alnoor Specialist Hospital, Makkah, Saudi Arabia.

Asma Al-Dosari, Pharm D, College of Pharmacy, Prince Nora University, Riyadh, Saudi Arabia

Asmaa Al-Fifi, Pharm D, College of Pharmacy, Prince Nora University, Riyadh, Saudi Arabia.

Razan Al-Dossari, Pharm D, College of Pharmacy, Prince Nora University, Riyadh, Saudi Arabia.

Haya Fahad bin Omar, Pharm D, College of Pharmacy, Prince Nora University, Riyadh, Saudi Arabia.

Huda Al-Jaziri, Pharm D, College of

Pharmacy, Prince Nora University, Riyadh, Saudi Arabia.

\section{Correspondence:}

Dr. Yousef Ahmed Alomi, BSc. Pharm, MSc. Clin Pharm, BCPS, BCNSP, DiBA, CDE, Critical care clinical pharmacists, TPN clinical pharmacist, Freelancer Business Planner, Content Editor and Data Analyst, P.O.BOX 100, Riyadh 11392, Riyadh, Saudi Arabia.

Phone no: +966504417712

E-mail: yalomi@gmail.com

Received: 22-08-2019;

Accepted: 09-11-2019

Copyright: $\odot$ the author(s),publisher and licensee Pharmacology, Toxicology and Biomedical Reports. This is an open-access article distributed under the terms of the Creative Commons Attribution NonCommercial License, which permits unrestricted non-commercial use, distribution, and reproduction in any medium, provided the original work is properly cited.

This is an open access article distributed under the terms of the Creative Commons Attribution-NonCommercial-ShareAlike 4.0 License

Access this article online

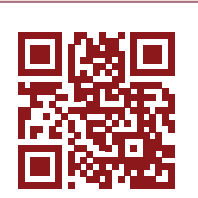

www.ptbreports.org

DOI:

10.5530/PTB.2020.6.4

\begin{abstract}
Objectives: To explore the pharmacist intervention documentation in the Kingdom of Saudi Arabia. Methods: This is a 4-month cross-sectional self-administrated survey on documentation of pharmacist intervention. The study consisted of two parts: the first part collected demographic information and the second part comprised of a questionnaire with 18 questions. The second part included policy and procedure, type of data through pharmacist intervention, reporting workload of pharmacist intervention documentation. All types of pharmacist professionals were included in this survey. We used a 5-point Likert response scale system to obtain the responses. There were open- and close-ended questions. The survey was distributed through the social media (WhatsApp) and other social media to more than 1000 pharmacist professionals in the Kingdom of Saudi Arabia. The survey was distributed in an electronic format and the data were analyzed through Survey Monkey system. Results: A total of 128 pharmacists responded to the survey. Of them, $106(82.81 \%)$ were Saudi and $22(17.19 \%)$ were nonSaudi professionals. The majority of the responders were in the age group of 25-34 years and 35-44 years (44.53\% and $25.00 \%$, respectively). Most of the responders had obtained Bachelor of Pharmacy $(40(31.25 \%))$ and Doctor of Pharmacy degree $(33(25.78 \%))$ and the majority of the pharmacists (112 $(87.50 \%))$ were not accredited by the Board of Pharmaceutical Specialty. The average score of the administration element of pharmacist intervention documentation was 3.68 (73.66\%). Policies and procedures of pharmacist intervention documentation obtained the highest score (4.13 (82.6\%)) followed by the quality management $(3.78(75.60 \%))$ and education with training $(3.76(75.20 \%))$. Adverse drug reactions $(92.86 \%)$ and medication errors $(91.19 \%)$ were most of the recorded type of documentation and poisoning information inquiries $(65.62 \%)$ and medication reconciliation $(80.31 \%)$ were the least type of documentation, with an average $54.66 \%$ documented electronically. Conclusion: The pharmacist intervention documentation was found to be acceptable in the Kingdom of Saudi Arabia. The half of pharmacist intervention documentations was an electronic only. In the future, we recommend to improve the system and correct barriers related issues. This will enhance the process of documentation and explore the impact and role of the pharmacist in the Kingdom of Saudi Arabia.

Key words: Pharmacist, Intervention, Documentation, Pharmacy, Workload, Saudi Arabia.
\end{abstract}

\section{INTRODUCTION}

Patient safety is of utmost importance to a healthcare provider, which they aim to achieve through minimization of adverse drug reactions and optimizing therapy management. ${ }^{1,2}$ To achieve this goal, a multi-disciplinary team is usually involved. Pharmacist is one of the healthcare providers who has the tremendous knowledge about medications. ${ }^{3-5}$ Moreover, pharmacists have diverse responsibilities such as monitoring medication for people with acute and chronic diseases, operating repeat prescription services, reviewing medication for long-term users, prescribing under protocols, advising on the management of common conditions and participating in local and national health promotion or disease prevention activities. ${ }^{6,7}$ Furthermore, the pharmacists ensure the rational and cost-effective use of medicines. ${ }^{8}$ In addition, they provide interventions that are considered as beneficial by the healthcare systems across various wards in the hospital..$^{9,10}$ Moreover, the implementation of pharmacist intervention documentations demand to declare the clinical and economic outcome of pharmacist's role toward patient care. Various studies have been conducted to evaluate pharmacist's intervention in preventing or reducing drug-related problems and reduced the potential economic burden. A cost avoidance study was conducted to identify pharmacist intervention in the emergency department through, dosage adjustment, responses to inquiries from nursing staff, therapeutic interchanges and suggestions of initiation of drug therapy. Moreover, The potential cost avoidance resulting of the pharmacist interventions was more than 1 million dollars. ${ }^{11}$ Abdulsalim et al. (2019) showed that medication adherence significantly increased after obtaining pharmacist intervention (from $49 \%$ to $80 \%$ after 2 years) $(P<$ $0.001)$. Moreover, documentation also increased medication adherence in patients with COPD. ${ }^{12}$ To enhance the productivity of their work, pharmacists should document the interventions provided to the patients. The documentation system should be a permanent medication record with rationale for providing the medication. The pharmacist's documentation helps to ensure continuity of care via communication among healthcare providers as subsequent team members are often not aware of the discussion. As the documentation system will create a permanent record, we can consider the documentation as an essential element during medico-legal cases. Therefore, for all these reasons, documentation of pharmacist intervention is a useful tool in improving the quality of the healthcare system; it not just benefits the patient but also the healthcare system. ${ }^{13}$ In 
addition, it is also an essential element to justify the salaries of the pharmacists and cost of clinical pharmacist activities, providing information to healthcare providers. ${ }^{14}$ Previous studies have focused on pharmacist intervention at governmental or private healthcare organization in Saudi Arabia. ${ }^{9,10,15,16}$ Moreover, several international studies have focused on methods and policies of pharmacist documentation. ${ }^{17-23}$ However, only a few studies have discussed the methods or types of pharmacist intervention documentation. ${ }^{24,25}$ Therefore, in this study, we aimed to explore the pharmacist intervention documentation system with an emphasis on planning of policies and procedures in the kingdom of Saudi Arabia (KSA).

\section{METHODS}

This is a 4-month cross-sectional self-administrated survey on documentation of pharmacist intervention. The study consisted of two parts: the first collected demographic information and the second part comprised a questionnaire with 18 questions. The questionnaire had domains on policies and procedures, type of data through pharmacist intervention, documentation of clinical impact and cost avoidance, analysis of pharmacist intervention and the barrier of pharmacist intervention documentation. All kinds of pharmacist professionals were included in this survey. We used 5-point Likert response scale system to obtain responses. There were open- and close-ended questions. The survey was distributed through social media (WhatsApp) in an electronic format and other social media to more than 1000 pharmacist professionals in the Kingdom of Saudi Arabia (KSA). The data were analyzed through the Survey Monkey system. The data were validated with the help of three methods. More than two authors reviewed the survey independently and the pilot study was conducted. The survey data were corrected accordingly. Cronbach's alpha test value for internal validity was calculated. This survey was exempted from the international guidelines of institutional review boards (IRB) ${ }^{26}$

\section{RESULTS}

A total of 128 pharmacists responded to the questionnaire. Of them, 106 $(82.81 \%)$ were Saudi and $22(17.19 \%)$ were non-Saudi professionals. The majority of the responders were in the age group of 25-34 years (44.53\%) and 35-44 years (25.00\%). Most of the responders had obtained Bachelor of Pharmacy $(40(31.25 \%))$ and Doctor of Pharmacy degree (33 $(25.78 \%))$ and the majority of pharmacists $(112(87.50 \%))$ were not certified by the Board of Pharmaceutical Specialties. The majority of the responders had more than 6 years of experience in pharmacy, clinical pharmacy and pharmacy administration (77 (60.16\%), 44 (20.47\%) and 39 (31.20\%), respectively) (Tables 1 and 2). The most of pharmacists were working at $=$ or $>600$ beds hospital $23(17.97 \%)$ and Medical City $22(17.19 \%)$ with the majority of the hospital had been accredited by Saudi Central Board for Healthcare Accreditation (CBAHI 84 (73.04\%) and by the US Joint Commotion (68 (59.13\%)) (Table 1). The average score of the administration element of pharmacist intervention documentation was 3.68 (73.66\%). Policies and procedures of pharmacist intervention documentation showed highest score $(4.13(82.6 \%))$ followed by the quality management $(3.78(75.60 \%))$ and education with training $3.76(75.20 \%)$ (Table 3$)$. The most type of documentation was for adverse drug reaction (92.86\%), medication errors (91.19\%) and pharmacist intervention (90.62\%), whereas the least type of documentation was for poisoning information inquiries $(65.62 \%)$ and medication reconciliation $(80.31 \%)$. The average score of manual documentation was $45.64 \%$, whereas the highest score was obtained for patient counseling $(52.76 \%)$, adverse drug reactions $(50.00 \%)$ and drug quality reporting (47.66\%). The average score on electronic documentation was $54.66 \%$, whereas the highest score on electronic documentation was obtained for medication errors (64.06\%), pharmacist intervention (63.28\%) and adverse drug reactions $(61.11 \%)$ (Table 4$)$. In the case of adult patients, the most reported workload of pharmacist intervention documentation was for number of medication errors (74.22\%) and number of prescriptions $(74.02 \%)$, whereas in the case of pediatrics, it was for number of prescriptions (63.28\%) and number of patients (63.28\%). The most reported workload documented in the case of neonates was for number of prescriptions $(45.31 \%)$ number of patients $(45.31 \%)$, number of medication errors $(45.31 \%)$ and number of adverse drug reactions $(45.31 \%)$ (Table 5). The Cronbach's alpha test value was 0.925 .

\section{DISCUSSION}

In Saudi Arabia, the pharmacist intervention documentation system had been started in mid-1990. ${ }^{25}$ This system allows the pharmacist to discuss any discrepancies with the physician regarding any prescriptions. As a result, from the past few years, the pharmacist is having an active role in the intervention and documentation of their rational activities and in designing a pharmacy intervention form for the purposes of documentation. A previous study has been conducted about 20 years ago regarding the pattern of documentation of pharmacist intervention and therefore an updated information about the pharmacist intervention is highly warranted. ${ }^{24}$ This study investigated the pharmacist intervention system related to the policies and methods of the documentation system. Our findings showed that in Saudi Arabia, the pharmacist intervention documentation related to the policies and procedures was acceptable. The most of recorded elements were policies and procedures, quality management and education and training of pharmacist. That previous barriers of pharmacist intervention were required for pharmacy and hospital services local and international accreditation. ${ }^{27,28}$ While the least recorded section was the competency of the pharmacy technician, which is related to the documentation of the intervention. The job of a clinical pharmacy technician is a new one for them to assess the documentation. The updated system is required to meet the updated things. There were various types of interventions that need to be documented. The three common type of documentation was for adverse drug reactions, medication errors and general pharmacist intervention..$^{25,29,30}$ they were documented manually or electronically. This is related to the requirements of quality management and accreditation by healthcare organization ${ }^{27,28}$ Moreover, the system of three type of pharmacist interventions are well established at the all healthcare services in the KSA. ${ }^{25,29,30}$

While drug poisoning documentation and medication reconciliation the least-recorded elements of documentation by either manual or electronic method, which might be related to the system or policy that does not exist. The updated version should have revised content for those elements. Drug information inquiry was the least-recorded electronic documentation because there is not a single electronic documentation system at most hospitals (they used Microsoft Excel to document). ${ }^{31}$ Half of the elements were documented electronically only. The electronic updated documentation is highly recommended with new Saudi Vision $2030 .{ }^{32,33}$ Based on the number of reporting of documentation, the highest documentation was recorded for prescriptions, number of patients and number of medication errors and pharmacist intervention. The documentation of patients and prescriptions was considered for workload documentation analysis, whereas medication errors of pharmacist intervention were required to prevent drug-related problems. Our findings showed that most of the type of patients documented their clinical activities were for adults followed by pediatrics and neonates. This might be because the documentation of adult patients already existed prior to pediatrics and neonates. ${ }^{34}$ The documentation of pharmacist intervention is a critical value in pharmacy practice. Regular future research about pharmacist intervention documentation is highly recommended in the KSA. 


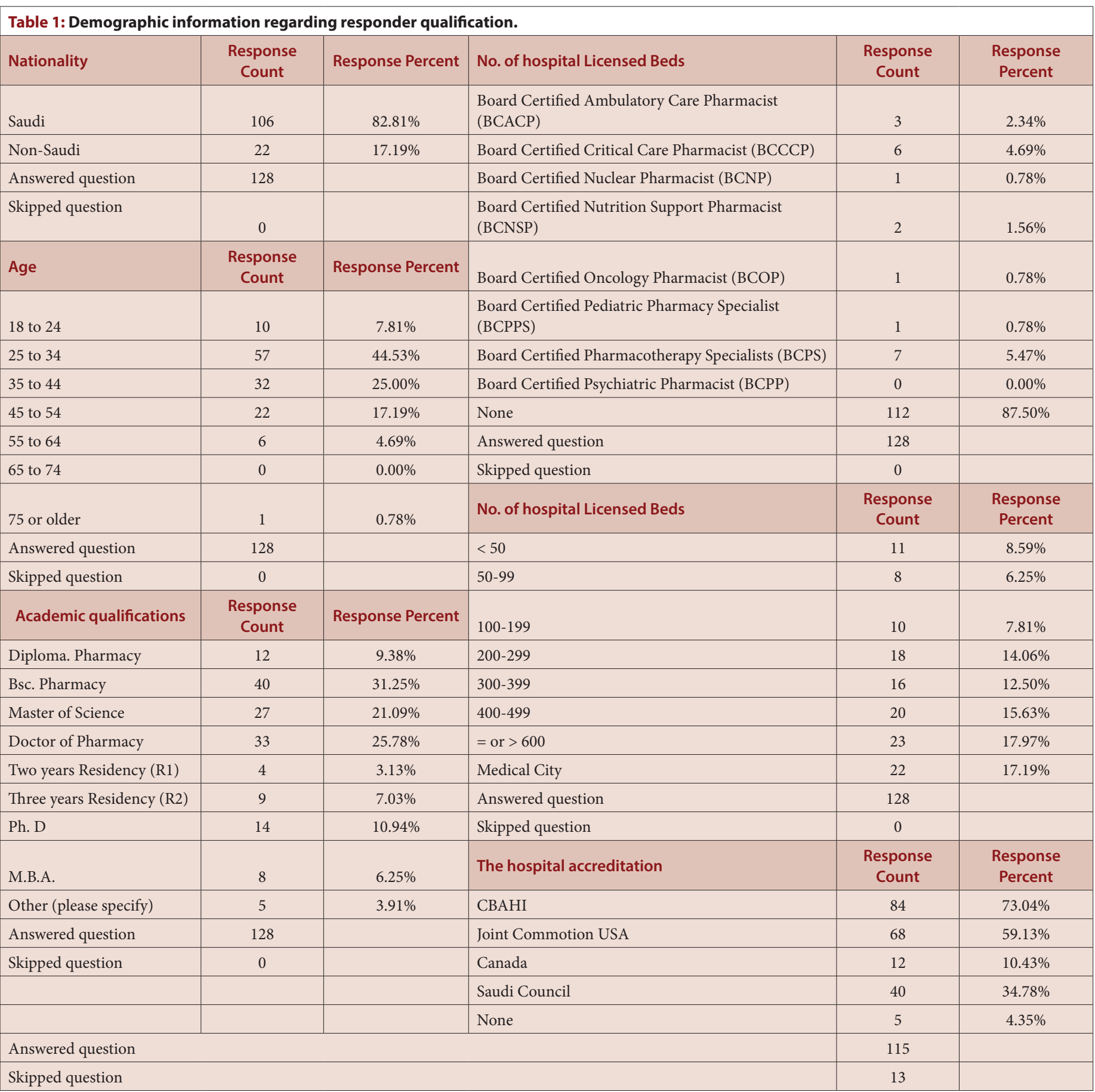

\section{ACKNOWLEDGEMENT}

None.

\section{CONFLICT OF INTEREST}

The authors declare no conflicts of interest.

\section{ABBREVIATIONS}

MOH: Ministry of Health; KSA: Kingdom of Saudi Arabia; CBAHI: Saudi Central Board for Healthcare Accreditation; COPD: Chronic Obstructive Pulmonary Disease; IRB: Institutional Review Board.

\section{ORCID}

Yousef Ahmed Alomi (iD https://orcid.org/0000-0003-1381-628X

\section{REFERENCES}

1. Alomi YA, Khayat AY, Jamil BM, Bamagaus YA, Mohammed H, Jumah A. National Survey of Hospital Medication Safety Practice during Mass Gathering (Hajj-2016) in Makkah, Saudi Arabia: Patient Information. J Pharm Pract Community Med. 2017;3(4s):S36-42.

2. Alomi YA, Almuallem ZA, Alslim MM, Alamoudi KA, Alragas HAM, Alslim RM National Survey of Medication Safety Practice: Patient Information at Primary Healthcare Centers/Community Pharmacies in Riyadh, Saudi Arabia. Pharmacol Toxicol Biomed Reports. 2019;5(1):36-43.

3. AHSP. ASHP statement on pharmaceutical care. Am J Hosp Pharm. 1993;50(50):1720-3 


\begin{tabular}{|c|c|c|}
\hline Years of Experiences in Pharmacy & Response Count & Response Percent \\
\hline$<1$ year & 15 & $11.72 \%$ \\
\hline $1-3$ years. & 19 & $14.84 \%$ \\
\hline 4-6 years. & 17 & $13.28 \%$ \\
\hline$>6$ year & 77 & $60.16 \%$ \\
\hline Answered question & 36 & \\
\hline Skipped question & 0 & \\
\hline Years of Experiences in Clinical Pharmacy & Response Count & Response Percent \\
\hline$<1$ year & 21 & $16.54 \%$ \\
\hline $1-3$ years. & 19 & $14.96 \%$ \\
\hline $4-6$ years. & 15 & $11.81 \%$ \\
\hline$>6$ year & 26 & $20.47 \%$ \\
\hline Non & 46 & $36.22 \%$ \\
\hline Answered question & 127 & \\
\hline Skipped question & 1 & \\
\hline Years of Experiences in Pharmacy Administration & Response Count & Response Percent \\
\hline$<1$ year & 19 & $15.20 \%$ \\
\hline $1-3$ years. & 17 & $13.60 \%$ \\
\hline 4-6 years. & 13 & $10.40 \%$ \\
\hline$>6$ year & 39 & $31.20 \%$ \\
\hline Non & 37 & $29.60 \%$ \\
\hline Answered question & 125 & \\
\hline Skipped question & 3 & \\
\hline
\end{tabular}

\begin{tabular}{|c|c|c|c|c|c|c|c|c|}
\hline Answer Options & $\begin{array}{l}75-100 \% \\
\text { completed }\end{array}$ & $50-74 \%$ & $25-49 \%$ & $1-24 \%$ & $\begin{array}{l}\text { We do not } \\
\text { have it }\end{array}$ & Rating Average & $\begin{array}{l}\text { Percent } \\
\text { Average }\end{array}$ & Response Count \\
\hline Strategic plan & 53 & 27 & 14 & 9 & 24 & 3.6 & 72.00 & 127 \\
\hline Annual plan & 51 & 27 & 15 & 10 & 24 & 3.56 & 71.20 & 127 \\
\hline Policy and procedure & 79 & 20 & 7 & 7 & 14 & 4.13 & 82.60 & 127 \\
\hline $\begin{array}{l}\text { Pharmacist intervention } \\
\text { competency }\end{array}$ & 49 & 32 & 18 & 9 & 20 & 3.63 & 72.60 & 128 \\
\hline $\begin{array}{l}\text { Pharmacy intervention } \\
\text { technician competency }\end{array}$ & 40 & 33 & 12 & 9 & 32 & 3.32 & 66.40 & 126 \\
\hline $\begin{array}{l}\text { Pharmacist intervention } \\
\text { quality management }\end{array}$ & 50 & 35 & 20 & 8 & 14 & 3.78 & 75.60 & 127 \\
\hline $\begin{array}{l}\text { Pharmacist intervention } \\
\text { Education and training }\end{array}$ & 51 & 33 & 19 & 10 & 14 & 3.76 & 75.20 & 127 \\
\hline Average & & & & & & 3.68 & 73.66 & \\
\hline \multicolumn{7}{|l|}{ answered question } & & 128 \\
\hline \multicolumn{7}{|l|}{ skipped question } & & 0 \\
\hline
\end{tabular}




\begin{tabular}{|c|c|c|c|c|c|c|c|}
\hline $\begin{array}{l}\text { Answer Options } \\
\text { Medication errors }\end{array}$ & \multicolumn{2}{|c|}{$\begin{array}{c}\text { Yes } \\
\text { manually }\end{array}$} & \multicolumn{2}{|c|}{$\begin{array}{c}\text { Yes } \\
\text { electronically }\end{array}$} & \multicolumn{2}{|c|}{ No } & $\begin{array}{c}\begin{array}{c}\text { Response } \\
\text { Count }\end{array} \\
128\end{array}$ \\
\hline Adverse drug reactions & 63 & $50.00 \%$ & 77 & $61.11 \%$ & 9 & $7.14 \%$ & 126 \\
\hline Drug quality reporting & 61 & $47.66 \%$ & 71 & $55.47 \%$ & 17 & $13.28 \%$ & 128 \\
\hline Drug information inquiries & 60 & $47.24 \%$ & 68 & $53.54 \%$ & 21 & $16.54 \%$ & 127 \\
\hline Poisoning information inquiries & 48 & $37.50 \%$ & 50 & $39.06 \%$ & 44 & $34.38 \%$ & 128 \\
\hline Medication Reconciliation & 50 & $39.37 \%$ & 69 & $54.33 \%$ & 25 & $19.69 \%$ & 127 \\
\hline \multicolumn{6}{|l|}{ answered question } & & 128 \\
\hline
\end{tabular}

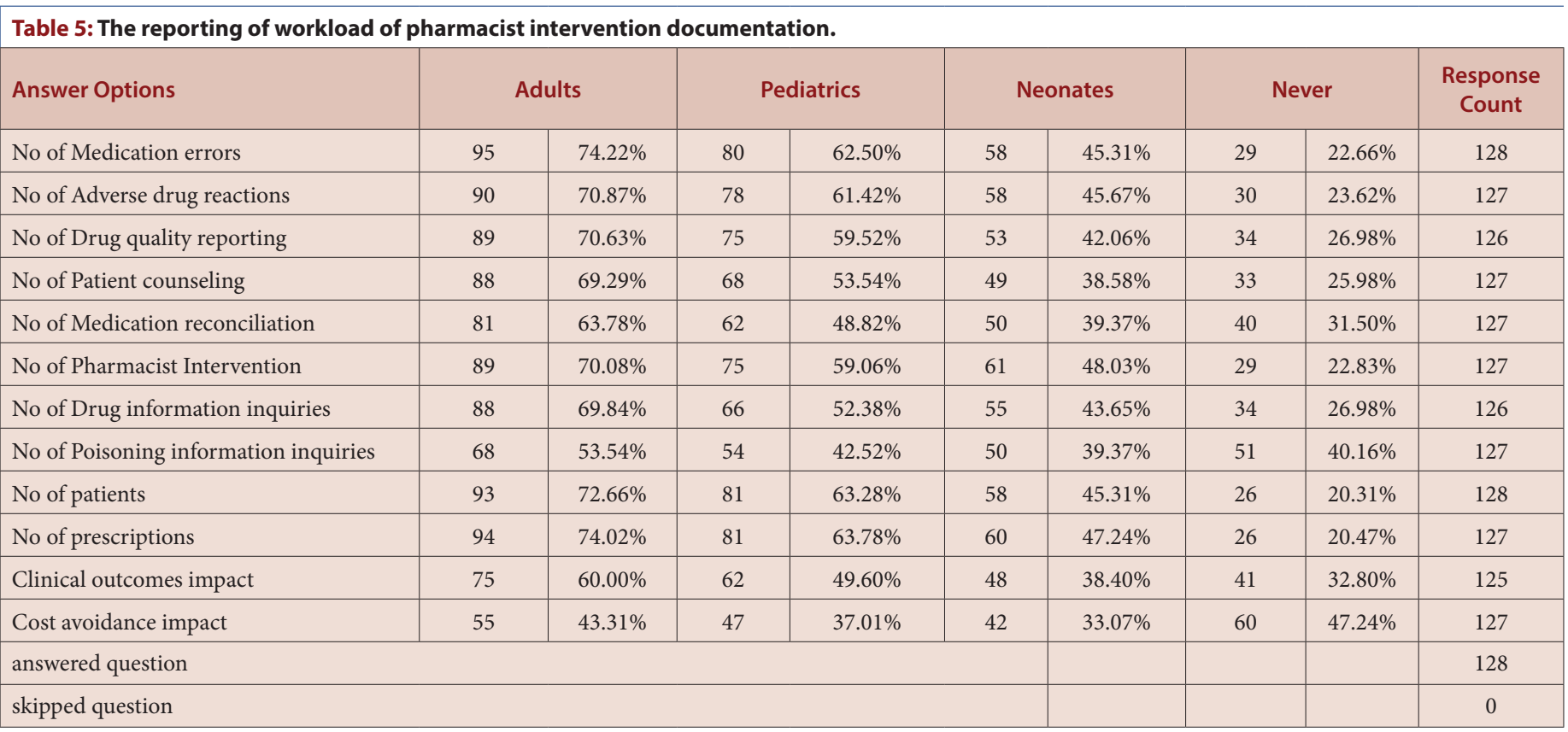

4. Ahmed AY, Adnan YKN, Jamil BM, Abdulraheem BY, Mohammed AJH. National Survey of Hospital Medication Safety Practice during Mass Gathering (Hajj2016) in Makkah, Saudi Arabia: Drug Information. J Pharm Pract Community Med. 2017;3(4s):S8-14

5. Alomi YA, Alslim MM, Alslim RM, Almuallem ZA, Alamoudi KA, Alragas AMH. National Survey of Medication Safety Practice: Drug Information at Primary Healthcare Centers/Community Pharmacies in Riyadh, Saudi Arabia. Pharmacol Toxicol Biomed Reports. 2019;4(3):37-42

6. American Society of Health-System Pharmacists. ASHP guidelines on a standardized method for pharmaceutical care. Am J Heal Pharm. 1996:53(14):1713-

7. Alomi YA, Alghamdi SJ, Alattyh RA. National Survey of Pharmacy Practice at MOH Hospitals in Saudi Arabia 2016-2017: Clinical Pharmacy Services. J Pharm Pr Community Med. 2018;4(1):1S-8S

8. Alomi YA, Alghamdi SJ, Alattyh RA. National Corporate Pharmacy and Therapeutic Committee at the Ministry of Health, Saudi Arabia. Pharmacol Toxicol Biomed Reports. 2019;4(3):24-7.

9. Alanazi1 AA, Alomi YA, Almaznai MM, Aldwihi M, Aloraifi IAK, Albusalih FA Pharmacist's Intervention and Medication Errors Prevention at Pediatrics, Obstetrics and Gynecology Hospital in East Province, Saudi Arabia. Int J Pharm Heal Sci. 2019;2(2):122-8.

10. Alomi YA, Alshabaar N, Lubad N, Albusalih FA. Inpatient Medication Errors and Pharmacist Intervention at Ministry of Health Public Hospital, Riyadh, Saudi Arabia. Pharmacol Toxicol Biomed Reports. 2019;5(1):44-8.
11. Lada P. Delgado G. Documentation of pharmacists' interventions in an emergency department and associated cost avoidance. Am J Heal Pharm. 2007;64(1):63-8.

12. Abdulsalim S, Unnikrishnan MK, Manu MK, Alrasheedy AA, Godman B, Morisky DE. Structured pharmacist-led intervention programme to improve medication adherence in COPD patients: A randomized controlled study. Res Soc Adm Pharm. 2018;14(10):909-14.

13. Simonian Al. Documenting pharmacist interventions on an intranet. Am J Heal Pharm. 2003;60(2):151-5

14. Alomi YA, Aldosary BA. Cost Analysis of Activities for Network Drug Information Centers at the Ministry of Health Hospitals in Saudi Arabia. Int J Pharm Heal Sci. 2019;2(1):45-51

15. Alomi1 YA, Fallatah AO, Al-Shubaar N, Qohal AA, Alameer LY. The Clinical Outcomes of Pharmacist Interventions in Total Parenteral Nutrition services in Riyadh City, Saudi Arabia. Int J Pharm Heal Sci. 2019;2(2):135-40.

16. Alomi YA, Fallatah AO, Bahadig FA, Qahtani AAAL. The Economic Outcomes of Pharmacist Interventions in Total Parenteral Nutrition Services in Saudi Arabia Pharmacol Toxicol Biomed Reports. 2019;5(3s):S40-9.

17. Ling JM, Mike LA, Rubin J, Abraham P, Howe A, Patka J, et al. Documentation of pharmacist interventions in the emergency department. Am J Heal Pharm. 2005;62(17):1793-7.

18. Fox BI, Felkey BG, Berger BA, Krueger KP, Rainer RK. Use of personal digita assistants for documentation of pharmacists' interventions: A literature review. 
Am J Heal Pharm. 2007;64(14):1516-25.

19. VoTH, Bardet JD, Charpiat B, Leyrissoux C, Gravoulet J, Allenet B, et al. Validation of a tool for reporting pharmacists' interventions in everyday community pharmacy. J Clin Pharm Ther. 2018;43(2):240-8

20. McNicol M, Kuhn C, Sebastian S. Standardized documentation workflow within an electronic health record to track pharmacists' interventions in pediatric ambulatory care clinics. J Am Pharm Assoc. 2019;59(3):410-5

21. Maes KA, Studer H, Berger J, Hersberger KE, Lampert ML. Documentation of pharmaceutical care: Validation of an intervention oriented classification system. J Eval Clin Pract. 2017:23(6):1425-32.

22. Kim Y, Schepers G. Pharmacist Intervention Documentation in US Health Care Systems. Hosp Pharm. 2003;38(12):1141-7.

23. Canaday BR, Yarborough PC. Documenting pharmaceutical care: Creating a standard. Ann Pharmacother. 1994;28(11):1292-6.

24. Alomi Y, Bakaerman N. Documentation pattern of clinical pharmacist intervention, Riyadh, Saudi Aarbia. In: ACCP Annual Meeting, October, USA. 2007.

25. Alomi YA, Alghamdi SJ, Alattyh RA. National Pharmacist Intervention Documentation System at the Ministry of Health in Saudi Arabia. Pharmacol Toxico Biomed Reports. 2019;4(3):31-3

26. The Office for Human Research Protections. Human Subject Regulations Decision Charts. Chart. 2016. [cited 2019 Nov 4]. Available from: https://www.hhs. gov/ohrp/regulations-and-policy/decision-charts/index.html
27. CIBAHI. Medication Management. In: National Accreditation Standred. $2^{\text {nd }}$ Edition. Saudi Central Board for Accreditation of Healthcare Institutions.; 2016. Available from: http://insights.ovid.com/crossref?an=01222928-201713010-00016

28. The Joint Commission. 2016 Comprehensive Accreditation Manuals. Joint Commission Resources. 2016.

29. Alomi YA, Alghamdi SJ, Alattyh RA. National Medication Errors Reporting System at Ministry of Health in Saudi Arabia. Pharmacol Toxicol Biomed Reports. 2019;5(1):4-7.

30. Alomi YA, Alghamdi SJ, Alattyh RA. National Adverse Drug Reaction Reporting System at the Ministry of Health, Saudi Arabia. Pharmacol Toxicol Biomed Reports. 2019;4(3):21-3

31. Alomi YA, Alghamdi SJ, Alattyh RA. National Survey of Pharmacy Practice at MOH Hospitals in Saudi Arabia 2016-2017: Pharmacy Computerized and Technology. J Pharm Pract Community Med. 2018;4(1s):s40-6

32. Alomi YA. New Pharmacy Model for Vision 2030 in Saudi Arabia. J Pharm Pract Community Med. 2017;3(3):194-6.

33. Alomi YA, Alghamdi SJ, Alattyh RA, Elshenawy RA. The Evaluation of Pharmacy Strategic Plan in Past 2013-2016 and Forecasting of New Vision 2030 at Ministry of Health in Saudi Arabia. J Pharm Pract Community Med. 2018;4(2):93-101.

34. Sanghera N, Chan PY, Khaki ZF, Planner C, Lee KKC, Cranswick NE, et al. Interventions of hospital pharmacists in improving drug therapy in children a systematic literature review. Drug Saf. 2006;29(11):1031-47. 